\section{Configuration of the $C / D$ Ring Junction in Equilenin and Other Steroids}

THE configuration of the $C / D$ ring fusion in equilenin has been the subject of a number of communications ${ }^{1-3}$. We consider that the arguments advanced for a trans ring junction leave much to be desired. Shoppee's ${ }^{1}$ conclusion that the dehydrogenation of equilin to equilenin under mild conditions proves the steric identity of the $C / D$ union in these two substances can no longer be accepted, since isoequilin, which is now known ${ }^{4,5}$ to be also trans, gives isoequilenin (which has the opposite $C / D$ configuration to equilenin) under the same conditions ${ }^{8}$.

It is evident that the same uncertainty is present in any correlation based on the formation of equilenin (or isoequilenin) by reactions involving a centre adjacent to $\mathrm{C}_{14}{ }^{2}$. One would anticipate epimerization at $\mathrm{C}_{14}$ in some of these experiments because of the possibility offered of relieving the strain associated with the trans $C / D$ hydrindane system.

Another attempt to correlate the $C / D$ configuration of equilenin with that of other natural steroids through a determination of the configuration at $\mathrm{C}_{\mathbf{1 4}}$ was based on the use of the method of molecular rotation differences ${ }^{3}$. Since this centre is adjacent to an unsaturated system which might give rise to considerable 'vicinal effect'?, the validity of this conclusion is questionable.

An unambiguous proof of the configuration of equilenin follows from the fact that Bachmann's ${ }^{8}$ $\alpha$-7-methoxy-2-methyl-2-carboxy-1,2,3,4 tetrahydrophenanthrene-1-acetic acid (III) (which was converted to isoequilenin) is obtained ${ }^{5}$ by hydrogen peroxide cleavage of the $\alpha$-diketone (I) to the diacid (II), followed by dehydrogenation. The diketone I is one of the products of the Diels-Alder reaction between 1-vinyl-6-methoxy-3,4-dihydronaphthalene and 3-methyl-cyclopentene-1,2-dione ${ }^{9,5}$, and must therefore be cis.

Dehydrogenation of II would not be expected to invert $\mathrm{C}_{1} \quad\left(\mathrm{C}_{14}\right.$ sterol numbering), since the strain associated with a trans hydrindane system is no longer present. Dehydrogenation experiments in the doisynolic acid series confirm this view ${ }^{10}$. The $C / D$ ring junction is therefore cis in isoequilenin and trans in equilenin.

Compound II proved identical with a diacid prepared by Miescher et al. ${ }^{2}$. This diacid, which is therefore unambiguously cis, gave after homologation and ring closure a substance which was not dl-isoequilin. Isoequilin is therefore trans, and its formation from equilin by acid isomerization cannot involve epimerization at $\mathrm{C}_{14}$ (which would have produced a cis compound). This means that the $C / D$ junction in œstrone must then also be trans, since it follows from the work of Pearlman and Wintersteiner ${ }^{11}$ that this junction is the same as that of equilin.

This derivation of the trans $C / D$ junction in cestrone can be used as chemical evidence for the trans $C / D$ union in the non-aromatic steroids, since cholesterol can be degraded to ostrone by a reaction which, although a pyrolysis, cannot involve $\mathrm{C}_{14}{ }^{12,13}$. This evidence is more convincing than that of Wieland and Dane ${ }^{14}$, which is open to serious eriticism ${ }^{15}$, or that of Dimroth and Jonsson ${ }^{26}$, which logically demonstrates only the fact that vitamin $\mathrm{D}_{\mathbf{2}}$ has a $C / D$ trans union, because the identity of the $C / D$ junction in vitamin $\mathrm{D}_{2}$ and ergosterol has not been convineingly demonstrated. It was possible that the trans $C / D$ vitamin $\mathrm{D}_{2}$ had resulted from the irradiation<smiles>COC(=O)C(=O)C1(C)CCC2=C(CCc3cc(OC)ccc32)O1</smiles><smiles>COc1ccc2c(c1)CCC1=C2CCC(C)(C(=O)O)[C@]1(CC(=O)O)C(=O)O</smiles><smiles></smiles>

of a cis $C / D$ ergosterol. Such a change to the less stable configuration is known ${ }^{17}$ to take place when isodehydrocholesterol, which is a $\mathrm{C}_{8} \alpha$-compound, is transformed during irradiation to the $\mathrm{C}_{\mathbf{8}} \beta$-configuration, which contains the less stable cis-decalin system.

\section{GIIBERT STORK}

GURbaKhSh Singh

Converse Memorial Laboratory,

Harvard University,

Cambridge 38,

Massachusetts. March 1.

${ }^{1}$ Shoppee, Nature, 161, 207 (1948).

${ }^{2}$ Rosenkranz, Djerassi, Kaufmann, Pataki and Romo, Nature, p. 814 of this issue.

${ }^{8}$ Klyne, Nature, 161, 434 (1948).

4 Heer, and Miescher, Helv. Chim. Acta, 31, 1289 (1948).

$\checkmark$ Singh, G., J. Amer. Chem. Soc. (in the press).

${ }^{6}$ Hirschmann, II., and Wintersteiner, J. Biol. Chem., 126, 737 (1938).

7 Barton, J. Chem. Soc., 783 (1948).

${ }^{8}$ Bachmann, Cole and Wilds, J. Amer. Chem. Soc., 62, 824 (1940).

- Dane and Schmitt, Ann., 537, 246 (1939).

so See, for example, Anner and Miescher, Helv. Chim. Acta, 30, 1422 (1947).

${ }^{11}$ Pearlman and Wintersteiner, J. Biol. Chem., 130, 35 (1939); 132, $605(1940)$.

${ }^{12}$ Inhoffen and Zühlsdorff, Ber., 74, 1911 (1941).

${ }_{13}$ Wilds and Djerassi, J. Amer. Chem. Soc., 68, 2125 (1946).

14 Wieland and Dane, Z. Physiol. Chem., 216, 91 (1933).

15 Peak, Nature, 140, 280 (1937).

${ }^{20}$ Dimroth and Jonsson, Ber., 74, 5201 (1941).

17 Windaus and Zühlsdorff, Ann., 536, 209 (1938). 